Short communication

\title{
Estimation of leaf area index in understory deciduous trees using digital photography
}

\author{
Francesco Chianucci*, Andrea Cutini, Piermaria Corona, Nicola Puletti \\ Consiglio per la Ricerca e la sperimentazione in Agricoltura-Forestry Research Centre, viale Santa Margherita 80, 52100 Arezzo, Italy
}

\section{A R T I C L E I N F O}

\section{Article history:}

Received 16 June 2014

Received in revised form 28 August 2014

Accepted 1 September 2014

\section{Keywords:}

Digital nadir photography

Foliage cover

Leaf angle distribution

Foliage projection coefficient

Leveled camera

\begin{abstract}
A B S T R A C T
Fast and accurate estimates of understory leaf area are essential to a wide range of ecological applications. Indirect methods have mainly been used to estimate leaf area of overstory but their application in understory remains largely unexplored. In this study we described a combination of digital photographic methods to obtain rapid, reliable and non-destructive estimate of leaf area index of understory deciduous trees. Nadir photography was used to estimate foliage cover, vertical gap fraction and foliage clumping index. Leveled photography was used to characterize the leaf angle distribution of the examined tree species. Leaf area index estimates obtained combining the two photographic methods were compared with direct measurements obtained from harvesting $(L)$.

We applied these methods in Quercus cerris, Carpinus betulus and Fagus sylvatica stands. Foliage cover estimates derived from two nadir image classification methods were significantly correlated with leaf area index measurements obtained from harvesting. The leveled digital photographic method, previously tested in tall trees and field crops, provided reliable leaf angle measurements in understory tree species. Digital photography provided good indirect estimates of $L$. We conclude that digital photography is suitable for routine estimate and monitoring of understory leaf area, on account of its fast and cost-effective procedure.
\end{abstract}

(c) 2014 Elsevier B.V. All rights reserved.

\section{Introduction}

Accurate estimates of leaf area index $(L)$ are essential to the ecological characterization of forest ecosystems (Chen et al., 1997) and for modeling stand structure and dynamics (Xue et al., 2011). Because direct measurements of $L$ in forests are destructive, timeconsuming and often impractical, indirect optical methods have been widely used to indirectly estimate $L$ from measurements of radiation transmittance through the canopy (for a review, see Bréda, 2003; Jonckheere et al., 2004; Welles and Norman, 1991). Beer-Lambert's law has often been used to model canopy transmittance (Eq. (1), based on Nilson, 1971):

$P(\theta)=\exp \left(\frac{-G(\theta) \times \Omega(\theta) \times L_{t}}{\cos \theta}\right)$

where $P(\theta)$ is the canopy gap fraction, $G(\theta)$ is the foliage projection coefficient and $\Omega(\theta)$ is the foliage clumping index at zenith angle $\theta$. $L_{t}$ is the plant area index, including foliar and woody materials.

\footnotetext{
* Corresponding author. Tel.: +390575 353021; fax: +39 0575353490 E-mail addresses: francesco.chianucci@entecra.it, fchianucci@gmail.com (F. Chianucci).
}

Over the last few decades, several comparisons have been made between direct and indirect methods to estimate the overstory leaf area index in forest ecosystems, as demonstrated in the previously cited reviews. However, very few attempts have been made to estimate the leaf area index of forest understory. Some studies showed that the understory leaf area may exceed that of the overstory (Law et al., 2001; Macfarlane et al., 2010). Accurate estimates of the understory leaf area index are also required for processedbased canopy photosynthesis models (Beaudet et al., 2002; Jolly et al., 2004), for designing silvicultural systems aimed at promoting natural tree regeneration (Caccia and Ballaré, 1998) and for understanding energy and mass exchange processes (Xue et al., 2011). As a consequence, rapid, non-destructive and reliable methods are strongly needed to estimate the understory leaf area index.

Thanks to recent technological development, digital cameras with high spatial and radiometric resolutions are becoming increasingly affordable and promote the use of digital photographic methods to indirectly estimate canopy structural variables such as gap fraction, foliage cover, leaf angle distribution and leaf area index. In addition, the digital image format is well suited to process photographs taken from above the canopy looking downward. For example, the use of vegetation indices has long been explored in crops and weed plants for indirectly estimating $L$ from 